\title{
AS ORGANIZAÇÕES DA SOCIEDADE CIVIL E AS ONGS DE EDUCAÇÃO
}

\author{
ANNA CYNTHIA OLIVEIRA \\ Consultoria independente para temas de governança e gestão de organizações da \\ sociedade civil - OSCs -, parcerias e responsabilidade social de empresas

\section{SÉRGIOHADDAD} \\ Associação Brasileira de ONGs - Abong -, Ação Educativa: Assessoria, Pesquisa e \\ Informação; Programa de Estudos Pós-Graduados em Educação da PUC-SP
}

\section{RESUMO}

Esta resenha de idéias e conceitos esclarece o leitor sobre uma sucessão de termos empregados livremente nos últimos tempos: sociedade civil, ONGs, Terceiro Setor, Lei das OSCIPS, conselhos paritários - o que vêm a ser, integrando a pauta da grande imprensa? Em abordagem simples, apresentam-se elementos da trajetória política das ONGs brasileiras dentro do cenário mais amplo da sociedade civil organizada. Discute-se o papel especial desempenhado por elas na longa luta pela socialização da educação, e seu atualíssimo dilema frente à onda de privatização de deveres constitucionais do Estado. ANÁLISE CONCEITUAL - SOCIALIZAÇÃO - EDUCAÇÃO - ONGS

\begin{abstract}
THE ORGANIZATIONS OF CIVIL SOCIETY AND THE NGOS IN EDUCATION. This teXt summarizes a series of concepts merely referred to by national press in recent years: civil society, NGOs, third sector, Law for CSOs of Public Interest, public policy councils - what are they, for the ordinary reader? In simple language, the authors highlight moments of the political trajectory of Brazilian NGOs and explain the niche they occupy in the broader nonprofit sector. They discuss the particular role NGOs have played in the struggle to democratize education, and the very present dilemma put by current governmental push to privatize constitutional duties.
\end{abstract}

Este artigo tem como base de referência, e de forma revisada, dois outros trabalhos: o de Haddad (1999) e o de Oliveira ( 1999), capítulo sobre a sociedade civil, em versão brasileira a ser publicada no Brasil este ano. 


\section{A SOCIEDADE CIVIL E SUAS ORGANIZAÇÕES}

Em seu uso mais tradicional, "sociedade civil" é parte de um binômio e faz contraponto com o Estado. Corresponde à população de cidadãos, ou esfera privada, e abrange suas variadas formas de organização e expressão - com ou sem fins lucrativos, podendo ser legalmente constituídas ou espontâneas e informais. $O$ conceito ganhou conotação política peculiar na América Latina, dos anos 70 para cá. ' Tornou-se típica da região a expressão "sociedade civil organizada", referindo-se ao fenômeno de participação crescente dos cidadãos em assuntos antes exclusivos à esfera pública, na defesa da justiça social e na promoção de causas de interesse geral. Junto com a nova expressão, disseminou-se o uso de "organizações da sociedade civil" - OSCs ${ }^{2}$ - para referir-se aos atores coletivos que expressam um sem-número de causas e interesses difusos da população, freqüentemente vinculados ao exercício mesmo da cidadania (Landim, Fernandes, 1988; Landim, 1993; Fernandes, 1994; Garrison, 2000).

Numa acepção mais contemporânea, portanto, sociedade civil organizada e OSCs confundem-se para designar o multifacetado universo das organizações constituídas livremente por cidadãos que atuam diante da carência de produtos e serviços que o Estado não atende de modo satisfatório e o mercado não tem interesse de atender. Pertencem a esse universo as organizações de base (grassroots) ou entidades comunitárias, voltadas para a promoção do desenvolvimento local e liderança de lutas populares; as organizações intermediárias de assessoria e pesquisa (think tanks) ou de defesa e promoção de direitos (advocacy); as fundações que realizam programas de interesse social ("operadoras") ou financiam projetos sociais realizados por terceiros (grantmakers); e as antigas entidades assistenciais, de atendimento direto a populações carentes, que praticam a filantropia em sentido estrito.

I. Contrapondo-se ao Estado de arbítrio da ditadura militar, a "sociedade civil" passou a remeter ao anseio pelo Estado de direito e a confundir-se com os contingentes de cidadãos que se opunham ao regime. Entre os ativistas do final da década de 70 - ligados à igreja católica, dirigentes de associações profissionais ou fundadores das primeiras ONGs de defesa de direitos , sucedeu-se simbólica e conceitualmente o uso das expressões "movimentos populares", "movimentos sociais" e "sociedade civil" ou "cidadania", conforme reviam seu próprio papel, representatividade e raio de influência (Fernandes, 1994, p.87-8).

2. O Banco Interamericano de Desenvolvimento - BID - incorporou o uso da expressão "organizações da sociedade civil" desde 1995, reconhecendo a acepção particular que podem ter as "organizações não governamentais" na América Latina. Assim, por exemplo, as ONGs peruanas e chilenas constituem categoria jurídica especial, sujeita a regime próprio. $\bigcirc$ Banco Mundial ainda prefere a expressão ONG, mas começa a referir-se a OSCs em documentos mais recentes. 
No Brasil, desde a conferência mundial da Organização das Nações Unidas ONU -, no Rio, conhecida como Eco-92, a imprensa assimilou o termo "organizações não governamentais" - $\mathrm{ONGs}^{3}$ - e passou a empregá-lo como sinônimo de entidades sem fins lucrativos. Ocorre que na América Latina é freqüente identificar como ONG uma classe especial de entidades que se dedica ao desenvolvimento participativo e sustentável e à construção e defesa de direitos. Seja no México, Costa Rica ou Colômbia, seja no Brasil, onde existe a Associação Brasileira de ONGs, essas organizações têm gênese própria e não se confundem com entidades comunitárias e de auto-ajuda, com centros de pesquisa, fundações e entidades filantrópicas de corte tradicional.

Por outro lado, nenhuma dentre essa miríade de organizações deve ser confundida com estabelecimentos de ensino privado e hospitais voltados exclusivamente para as elites, clubes sociais ou de futebol, fundos de pensão, algumas seguradoras e alguns planos de saúde, igrejas e cultos, organizações profissionais e corporativas, inclusive sindicatos, centrais e federações. Esse mundo de entidades tem origens, propósitos e práticas diferentes, embora a legislação brasileira admita que não distribuem lucros e lhes confira esse denominador comum. ${ }^{4}$ Para analisar as OSC é freqüente a exclusão ainda que empírica - de muitos desses segmentos.

É justamente pela dificuldade de determinar um recorte adequado que o uso popular do termo "terceiro setor", outra vez confundindo tudo que seja sem fins lucrativos, encontra a resistência de especialistas. O novo conceito substituiria o clássico binômio Estado/sociedade civil, por um tripé: Estado/mercado/sociedade civil - esta última, agora, entendida como uma "terceira esfera", numa interseção entre o espaço público e o privado, reunindo virtudes de ambos para a promoção do bem comum.

Dados disponíveis sobre a sociedade civil organizada, no Brasil, estão dispersos por redes e associações de OSCs. Seu escopo global é impossível de determinar, a menos que se misture toda sorte de entidades sem fins lucrativos porque esta é a única

3. A alcunha $O N G$ provém do sistema $O N U$, e foi incorporada pelo Banco Mundial para designar praticamente toda entidade que não pertença ao aparelho de Estado.

4. Sobre o que se tem chamado de "setor sem fins lucrativos" , foi pioneira a pesquisa realizada por Leilah Landim e Sérgio Goes de Paula, em 1991, junto à Receita Federal. As 220 mil entidades registradas no Cadastro Geral do Contribuinte - CGC - como sem fins lucrativos encontravam-se classificadas do seguinte modo: $29,1 \%$ eram "beneficentes, religiosas e assistenciais"; 23,3\%, "esportivas e recreativas"; 18,6\%, "culturais, científicas e educacionais"; 4,4\%, "assistenciais e recreativas"; 18,6\%, "culturais, científicas e educacionais"; 4,4\%, "associações e sindicatos de empregados"; $2,9 \%$, "associações e sindicatos de empregadores"; । ,8\%, "associações de autônomos ou profissionais liberais"; e nada menos que 19\% eram, simplesmente, "outras" (Landim, Beres, 1999, p.20). 
chave existente nos cadastros de órgãos governamentais. Com base em dados agregados oficiais, de 1995, sabe-se que cerca de I , I 2 milhão de pessoas prestaram trabalho remunerado ao "setor sem fins lucrativos", alcançando a marca de I,5 milhão de indivíduos ocupados quando se somam os voluntários. As despesas operacionais desse mundo de organizações quase atingiram $\mathrm{R} \$$ I I bilhões no mesmo ano, ou I,5\% do Produto Interno Bruto - PIB - nacional. Do lado da receita, quando se exclui o segmento diretamente vinculado a religiões, o volume gerado como receita própria pelas organizações foi de 73,5\%, enquanto o governo participou com I 5,7\% e o recebimento de doações privadas participou com apenas $10,9 \% .^{5}$

Um volume tão grande de recursos próprios seria surpreendente para as OSCs, mas um apanhado das fontes de recursos tomando como base cadastros parciais, organizados por elas mesmas, mostra a distorção de dados agregados como esses. Tomemse, por exemplo, as entidades associativas como o Grupo de Institutos, Fundações e Empresas - Gife - e a Associação Brasileira de ONGs - Abong -, por seu peso político e reconhecimento internacional. As cerca de 60 organizações representadas pelo Gife podem ser consideradas auto-sustentadas, em sua maioria, não pela venda de produtos e serviços mas porque manejam recursos provenientes das empresas que as instituíram. Muitas delas aliás são fonte de doações privadas para outras entidades, cujos projetos correspondem a suas áreas de atuação. Por sua vez, as quase 270 ONGs, representadas pela Abong, dependem majoritariamente de doações recebidas de agências internacionais não governamentais (76\% dos recursos movimentados em 1994). Os aportes do governo federal, estadual ou municipal tiveram participação desprezível em seu orçamento, com 3,2\% no mesmo ano (site: www.gife.org.br; Landim, Cotrim, 1996). No entanto essa participação tem sido crescente nos últimos anos, particularmente em relação aos recursos federais. Em 1997, 50\% das ONGs associadas à Abong receberam recursos públicos.

Apesar da ausência de estatísticas adequadas, é fato que a diversidade, visibilidade e poder de fogo das OSCs destacam positivamente o Brasil como democracia vibrante no cenário latino-americano. É importante lembrar que a influência que elas exercem cresce exponencialmente graças a sua articulação em muitas redes. Múltiplas e transversais, intercombinadas, as redes de OSCs canalizam intenso fluxo de informações e permitem a sinergia e o reforço mútuo (Fernandes, 1994, p. 129-30). São locais, regionais e internacionais, e proliferaram com redobrada eficiência na medida em que se

5. Na determinação do porte do setor sem fins lucrativos, a pesquisa considera como pertencentes à "área Religião" as "igrejas, ordens, pastorais, paróquias, centros de cultos etc.", que concentram maior proporção de doações por indivíduos (Landim, Beres, 1999, p.49). 
difundiu o uso do e-mail, seguido pelo acesso à Internet. Redes temáticas de alcance nacional são, por exemplo, o:

- Fórum Brasileiro de ONGs e Movimentos Sociais para o Meio Ambiente e o Desenvolvimento (cerca de 130 membros);

- Fórum Nacional Permanente de Entidades Não-Governamentais de Defesa dos Direitos da Criança e do Adolescente - Fórum DCA (perto de 70 organizações);

- Movimento Nacional de Direitos de Humanos - MNDH (congrega 250 entidades); a Rede Nacional de AIDS/ONGs (com mais de 200 organizações);

- Fórum Nacional de Entidades Civis de Defesa do Consumidor (perto de 20 associações);

- Fórum Nacional pela Reforma Agrária e Justiça no Campo, no qual se reúnem o Movimento dos Sem-Terra - MST -, a Confederação de Trabalhadores daAgricultura - Contag - e a Comissão Pastoral da Terra - CPT (Garrison, 2000, p. 19).

É hoje praticamente universal o entendimento de que

...a existência de OSCs de variada índole concretiza a liberdade constitucional de associação e que um setor civil forte é reflexo do respeito ao pluralismo e à expressão de legítimas diferenças, assim como do exercício da tolerância como princípio de convivência social. (Oliveira, 1997, p.4)

A multiplicidade de atores, em todos os níveis, conforma o rico "capital social" do país (Putnam, 1993), assegurando a expressão da diversidade cultural e das profundas desigualdades sociais existentes no Brasil.

Conceitos como esses foram rapidamente absorvidos pela agenda política das agências que adotam o sistema $\mathrm{ONU}$. E não tardou muito para que fossem incorporados ao discurso oficial de outros organismos, impermeáveis há alguns anos. A existência de uma extensa malha de entidades passou a ser crescentemente valorizada como condição para o desenvolvimento sustentado. ${ }^{6}$ Da parte do Banco Mundial, do Banco Interamericano do

6. Numa iniciativa que pode ser vista como celebração do novo paradigma, as representações de Programa das Nações Unidas para o Desenvolvimento - PNUD e do BID, na Argentina, preparam piloto do Índice de Desenvolvimento da Sociedade Civil - IDSC -, destinado a determinar a riqueza dessa malha de organizações por uma variedade de indicadores (PNUD, e BID, 1998). Medindo a vitalidade da sociedade civil organizada em qualquer país ou região, - IDSC permitirá confrontações com o Índice de Desenvolvimento Humano - IDH - do PNUD. A inter-relação de ambos fará crescer o respaldo oficial para o fortalecimento da sociedade civil organizada em todo o mundo. 
Desenvolvimento - BID - e, por último, do Fundo Monetário Internacional - FMI -, parece consensual o entendimento de que programas de erradicação da pobreza e do desenvolvimento requeiram o engajamento ativo da sociedade civil, sob pena de ineficácia. Atribui-se papel chave às OSCs, tanto comunitárias como intermediárias (as ONGs); busca-se envolvê-las em projetos oficiais, reconhecendo nelas competência peculiar. Teses como o "empoderamento" de populações economicamente marginais na condição de protagonistas do próprio desenvolvimento, o imperativo da transparência e da publicidade no uso de fundos públicos, a consulta na formulação de políticas, o recurso a ouvidorias e a audiências públicas, o controle social - são antigas convicções das ONGs, particularmente caras às latino-americanas, que alcançam, hoje, unanimidade surpreendente.

Em sintonia com as novidades do pensamento político agora corrente, o ConseIho da Comunidade Solidária (site: www.comunidadesolidaria.org.br) propugna em recente documento, "um novo referencial para a ação social do Estado e da sociedade" no Brasil, com o propósito de alimentar discussões de mais uma rodada de interlocução política. O documento alinha e desenvolve sete enunciados, entre os quais:

- Não há contradição entre dever do Estado e responsabilidade do cidadão;

- Não há contradição entre políticas públicas e dinâmicas comunitárias, entre oferta de serviços e fortalecimento do capital social local;

- Não há, ou não deveria haver, contradição entre política econômica e política social;

- Compartilhar com a sociedade as tarefas de formulação e implementação de uma estratégia de desenvolvimento social não é apenas uma possibilidade mas uma necessidade na sociedade contemporânea.

\section{As OSCs de interesse público e a "lei do terceiro setor"}

No vasto panorama das OSCs, é preocupação corrente destacar aquelas que propugnam fins públicos, beneficiando um amplo espectro da população, sem, contudo, abrir mão da independência e autodeterminação asseguradas às organizações livremente estabelecidas com o amparo da Constituição. Complementando a ação do Estado na esfera pública, o segmento mereceria incentivos fiscais especiais e recursos públicos que financiassem seus programas de cooperação com o governo. A caracterização de OSCs de fim público é clássica em países de tradição anglo-saxônica mas permanece como desafio na América Latina. Trata-se de

...distinguir aquelas que têm por objetivo a defesa ou promoção de interesses de seus membros ou instituidores de outras que, beneficiando populações-meta que 
estão além da própria instituição, perseguem fins públicos ou promovem interesses sociais difusos. À primeira vista, saltam exemplos de umas e outras; mas a identificação é tarefa complexa, pela variedade de fins e áreas de atuação dessas entidades, que muitas vezes desempenham atividades com ambas as conotações. (Oliveira, 1997a, p. 13)

No Brasil, a legislação que regula as OSCs é um cipoal de normas construído a partir do Código Civil de 1916, ao sabor das circunstâncias políticas e lobbies setoriais. Não existe uma tipologia das entidades sem fins lucrativos, mas frouxas categorias criadas por leis sucessivas para atribuir privilégios a grupos bem articulados de organizações. $\mathrm{Na}$ ausência de tipos legais, uma caracterização pragmática das OSCs de fins públicos somente seria possível se as poucas estatísticas oficiais usassem nomenclatura racional para classificar o enorme contingente das entidades sem fins lucrativos.

Determinar uma classificação contemporânea que separasse "o joio do trigo" foi uma das preocupações do Conselho da Comunidade Solidária em rodada de interlocução política entre governo e sociedade civil, lançada em 1997, visando o encaminhamento de reforma à legislação para dar reconhecimento e regime especiais às organizações de fins públicos. Do esforço de cerca de um ano resultou projeto de lei ao qual faltaram disposições sobre incentivos tributários ou fundos orçamentários de apoio, rechaçadas pelo governo. O projeto, encaminhado pela Secretaria da Casa Civil à Câmara de Deputados, em julho de 1998, foi promulgado em março de 1999, com poucas emendas, na forma da Lei n.9.790, de 23.3.99, divulgada na imprensa como a "nova lei do terceiro setor".

A Exposição de Motivos do Projeto de Lei n.4.690, de 28.7.98, assinada pelo Chefe da Casa Civil e Ministros da Fazenda, da Previdência e da Justiça, propugnava "o fortalecimento do Terceiro Setor, no qual se incluem as entidades da sociedade civil de fins públicos e não lucrativos", na condição de "orientação estratégica nacional em virtude da sua capacidade de gerar projetos, assumir responsabilidades, empreender iniciativas e mobilizar recursos necessários ao desenvolvimento social do país". Afirmava ser necessária uma "inflexão na relação entre as organizações do Terceiro Setor e o Estado", reconhecendo que a expansão do setor dava origem a uma nova "esfera pública não estatal”. Reconhecia a diferença entre a natureza das organizações de benefício mútuo e as de interesse público, admitindo que as últimas mereceriam incentivos fiscais e acesso a recursos públicos por mecanismos justos e transparentes que substituíssem a sucessão de filtros burocráticos, tais como o título de utilidade pública, o registro no Conselho Nacional de Assistência Social e o Certificado de Entidade de Fins Filantrópicos.

Para a nova categoria de OSCs, a lei estabeleceu inovações relevantes no que se refere à transparência e à confiança pública. Sob pena de perderem a qualificação de OSC de Interesse Público - OSC-IP -, essas entidades não podem envolver-se em atividades 
político-partidárias, são obrigadas a se submeter à auditoria anual e a tornar públicas suas demonstrações financeiras, bem como seus relatórios de atividades. Ainda, como medida necessária à qualificação, junto à Coordenação de Outorgas e Títulos da Secretaria Nacional de Justiça - SNJ - do Ministério da Justiça, a assembléia geral de sócios ou conselho dirigente da entidade interessada deve aprovar reforma estatutária que estabeleça políticas internas suficientes para garantir a observância de princípios de impessoalidade, publicidade, economicidade e moralidade. ${ }^{7}$ A pauta obrigatória para o exercício de autoregulação vai mais longe. Os estatutos encaminhados à SNJ para aprovação devem dispor, explicitamente: quanto à prevenção de conflitos de interesse e combate ao proveito pessoal por parte de dirigentes e administradores com poder de decisão; quanto à submissão de todas as contas ao escrutínio de um conselho, de caráter interno, que emita parecer à instância máxima de direção da entidade; quanto a uma política de remuneração adequada, compatível com o mercado de trabalho da mesma base geográfica, para os dirigentes que desempenham papel executivo ou prestam serviços de natureza eventual (Oliveira, 1998a).

O novo regime aplica-se apenas às entidades que se qualifiquem como OSC-IPs, e para elas há somente um atrativo: tornam-se elegíveis para celebrar "termos de parceria" com os poderes públicos, instrumento que deveria substituir os convênios e os contratos, simbolizando uma renovação substantiva de antigas relações. $\bigcirc$ termo de parceria suscitou interesse de especialistas no tema da cooperação Estado/sociedade civil, inclusive do BID e do Banco Mundial. Entende-se que deve documentar relações de aliança entre partes assumidamente distintas, mas que reconhecem competências complementares uma na outra e se respeitam mutuamente. ${ }^{8}$ Tratando-se de aportes públicos a entidades privadas, mecanismos de supervisão e publicidade nunca vistos nos antigos convênios foram postos pela Lei n.9.790 e seu regulamento, ${ }^{9}$ o Decreto n. 3. 100 de 30.6.99. A grande omissão das novas regras está no procedimento neces-

7. Os abrangentes princípios de gestão provêm do caput do artigo 37, da Constituição Federal, que os enuncia como norma elementar da administração pública.

8. Mas não basta forma nova para criar conteúdo novo. A essência inovadora da parceria não consta de nenhum dispositivo da lei ou do regulamento, ficando ao sabor da sensibilidade de cada "órgão parceiro".

9. A novidade serviu bem ao atual governo de Pernambuco: diante da prática generalizada da distribuição discricionária de subvenções parlamentares - sangrando $R$ \$ 12,96 milhões/ano dos cofres públicos - a entidades da preferência pessoal dos 54 deputados, o governador conseguiu fazer com que eles mesmos aprovassem, num "cochilo", lei estadual que as converteu a todas em OSC-IPs e obrigou-as a firmar termos de parceria com o Executivo para continuar recebendo ditos recursos (Borges, 2000). 
sário à seleção de OSC-IPs com quem celebrar o termo: a escolha compete a cada órgão do governo, livremente, com a única formalidade de fazer tramitar consulta junto ao conselho nacional de política pública da área correspondente ao objeto da parceria. Independentemente do resultado da consulta, o "órgão parceiro" é quem detém a palavra final.

\section{Participação de OSCs no espaço público e controle social}

Ao longo dos anos 70 e 80, a proliferação exponencial das OSCs na América Latina promoveu e se beneficiou, ao mesmo tempo, do colapso das ditaduras. Os regimes militares haviam se firmado sobre raízes populistas, mas desmantelado ou reduzido os espaços de negociação política em nome da segurança nacional. Ea

... democratização não se fez sob a égide da restauração. Em vez de voltar aos padrões anteriores, prosseguiu no caminho de desestruturação da herança populista. Abriu-se para novas competições políticas; promoveu a convocação de assembléias nacionais constituintes (...), e aderiu às estratégias neoliberais de política econômica. (Fernandes 1994, p.92-3)

A famosa "década perdida" dos 80 assistiu aos ajustes estruturais e viu crescerem os índices de pobreza. A deterioração dos serviços públicos e o abandono à própria sorte de contingentes crescentes da população levaram ao descrédito o governo, a classe política e um inoperante sistema judicial. O ambiente de crise institucional estimulava as iniciativas de auto-ajuda, solidariedade e soluções alternativas para carências que o Estado deixara de suprir. Ao mesmo tempo em que pipocam as associações comunitárias, no enfrentamento de problemas locais, fortalecem-se as entidades intermediárias que lhes oferecem assessoria e capacitação. São as ONGs, que se dispõem a vigiar criticamente o Estado, lutando para se fazer ouvir na formulação de políticas públicas e prontas a oferecer propostas inovadoras de atuação a partir de seus próprios projetos experimentais, financiados pela chamada cooperação internacional, uma teia de organizações não governamentais (principalmente européias e, em sua maioria, vinculadas a igrejas - ecumênicas, evangélicas e católicas) do hemisfério norte (Fernandes, 1994, p.79-85).

No Brasil, o rompimento com o passado não se refletiu na legislação que afeta o terceiro setor. A despeito das convulsões do cenário político, algumas disposições provêm do Estado Novo (data de 1935 a lei de utilidade pública, vigente até hoje) ou foram introduzidas pela Constituição democrática de 1946 e nunca desapareceram, como é o caso da imunidade de alguns impostos para instituições de educação e assistência social. A isenção do imposto de renda foi disciplinada em lei ordinária de 1946 e incorporada ao 
Código Tributário Nacional em 1966 (em plena ditadura, portanto), mantendo-se praticamente ainda nos mesmos termos. A isenção da contribuição patronal ao Instituto Nacional de Seguro Social - INSS - foi introduzida em 1959, regulamentada em 1962 (quando se introduziu o Certificado de Entidade de Fins Filantrópicos) e revogada pelo General Ernesto Geisel em 1977 - mas o princípio constitucional existia desde 46 e foi repetido pela Constituição de 88 , de modo que a isenção voltou à cena, com o relançamento do mesmo certificado, em 1993 (Oliveira 1997a ). Mas foi graças ao tremendo esforço de articulação das OSC s que teses mais modernas para a colaboração entre Estado e sociedade civil foram incorporadas à Constituição de 1988. A cooperação de organizações da sociedade civil é explicitamente prevista - embora sob confusa denominação - ao longo de todo o título dedicado à Ordem Social, nos capítulos que tratam da seguridade social (áreas da saúde e da assistência social), da educação, da família, da criança e adolescente e do idoso (Constituição Federal de 1988, especialmente artigos 199-parágrafo primeiro, 204-inciso I, 213 , e 227-parágrafo primeiro). Surge também a figura dos primeiros conselhos paritários de políticas públicas, composta por representantes do governo e da sociedade civil, com a finalidade de formular políticas e controlar ações em todos os níveis na área da assistência social e atender especialmente a criança e o adolescente ( idem, artigos 204-inciso Il e 227-parágrafo sétimo).

Essa é a origem dos conhecidos Conselhos da Assistência Social e dos Direitos da Criança e do Adolescente, regidos por legislação ordinária espećfica, com base nos preceitos constitucionais, para operar de modo descentralizado nos três níveis da federação.

O Conselho Nacional da Assistência Social - CNAS - integra a estrutura do Ministério da Previdência Social e Assistência Social, e nele têm assento: sete representantes da administração pública federal (indicados pelos Ministérios da Previdência e Assistência Social, Trabalho, Saúde, Educação, Fazenda, Planejamento e Orçamento e pela Secretaria Nacional de Assistência Social/MPAS); um representante dos estados e um dos municípios; e dezesseis representantes da sociedade civil, representação distribuída entre (a) entidades e organizações de assistência social, (b) usuários ou organizações de usuários e (c) trabalhadores da área de assistência social, sendo três titulares e três suplentes por segmento. ${ }^{10}$

10. A "bancada da sociedade civil" no CNAS, eleita em abril de 2000, é composta pelas seguintes entidades: Confederação das Santas Casas de Misericórdia, Hospitais e Entidades Filantrópicas, Conferência Nacional dos Bispos do Brasil - CNBB e Associação de Apoio à Criança e ao Adolescente - Amencar (titulares), mais Federação Nacional das Sociedades Pestalozzi - Fenasp -, Federação Brasileira de Instituições de Excepcionais de Integração Social e de Defesa da Cidadania - Febiex e Igreja Presbiteriana do Brasil (suplentes), na condição de representantes das entidades e organizações de assistência social; Federação Brasileira das Associações Cristãs de 
O Conselho Nacional dos Direitos da Criança e do Adolescente - Conanda integra a estrutura do Ministério da Justiça e tem por competência "formular a política de atendimento a direitos da criança e do adolescente; controlar as ações públicas governamentais e não governamentais decorrentes dessa política, isto é, acompanhar (monitorar), analisar, avaliar e responsabilizar (encaminhar aos órgãos competentes em caso de aplicação de sanções ou de correção); mobilizar a sociedade em favor da defesa dos direitos da criança e do adolescente" ( "Competências", página do Conanda, web site: wnw.mj.gov.br).

Participam do Conanda: do lado do governo, os Ministérios da Justiça, das Relações Exteriores, da Educação, da Saúde, da Fazenda, do Trabalho e Emprego, da Previdência e Assistência Social, da Cultura, do Orçamento e Gestão, e a Casa Civil da Presidência da República, com um titular e um suplente cada qual; e, pela sociedade civil, dez organizações titulares seguidas de dez suplentes. ${ }^{\text {' }}$

Paralelamente, surgem novas instâncias mistas com poder deliberativo, visando engajar a sociedade na formulação de políticas setoriais. Entre elas:

- o Conselho Nacional do Meio Ambiente - Conama -, criado por lei anterior à nova Constituição mas instalado por regulamentação de 1990, na condição de órgão consultivo e deliberativo do Sistema Nacional do Meio Ambiente / Ministério do Meio Ambiente (web site: www.mma.gov.br);

Moços - FBACMs -, Federação Nacional das Associações de Pais e Amigos dos Excepcionais FNAPAEs - e Pastoral da Criança (titulares), mais Federação Brasileira de Entidades de Cegos Organização Nacional de Entidades de Deficientes Físicos - Onedef - e Confederação Israelita do Brasil (suplentes), na condição de representantes dos usuários ou de organizações de usuários; e ainda Conselho Federal de Serviço Social - CFESS -, Associação Nacional de Sindicatos Social-Democratas e Confederação Nacional dos Trabalhadores em Seguridade Social da Central Única dos Trabalhadors - CNTSS/CUT(titulares) -, mais Força Sindical e Federação Nacional dos Psicólogos (suplentes, ficando vaga a terceira suplência), todas essas como representantes dos trabalhadores da área de assistência social (fonte: Ato n. 3, de 26/4/ 2000, firmado pela Junta Eleitoral "designada para a eleição dos membros da sociedade civil" do CNAS, disponível no web sitewww.mpas.gov.br).

I I. Conforme Lista de Conselheiros, de 10.7.2000, ibidem. Em nome da sociedade civil, são estas as entidades: Fundação Fé e Alegria, PUC/SP, Sociedade Brasileira de Pediatria, CUT, Movimento Nacional dos Direitos Humanos, Amencar, Abong, CFESS, Centro de Cultura Luiz Freire e CNBB, na condição de titulares; mais Instituto para o Desenvolvimento Integral da Criança e do Adolescente - Indica -, Centro de Referência, Estudos e Ações sobre Crianças e Adolescentes Cecria -, Associação Brasileira de Magistrados e Promotores da Justiça, da Infância e da Juventude - ABMP -, Pastoral da Criança/CNBB, Confederação Evangélica Nacional de Ação Social/MEN, Inspetoria São João Bosco/Salesianos, Fundo Cristão para Crianças, Organização Mundial para Educação Pré-Escolar - OMEP -, Confederação Nacional dos Trabalhadores em Educação - CNTE - e Federação das Bandeirantes do Brasil, como suplentes. 
- o paritário Conselho Nacional dos Direitos da Pessoa Portadora de DeficiênciaConade -, criado recentemente no âmbito do Ministério da Justiça para acompanhar e avaliar as políticas setoriais de educação, saúde, trabalho, assistência social, transporte, cultura, turismo, desporto, lazer e política urbana no que concerne aos portadores de deficiência (web site: wnw.mj.gov.br).

Outros conselhos relevantes incluem experiências anteriores à última Assembléia Constituinte. Com caráter consultivo, integrando o organograma do Ministério da Justiça, o Conselho de Defesa dos Direitos da Pessoa Humana - CDDPH - tem composição representativa do governo e da sociedade civil que remonta a 1964. É presidido pelo Ministro da Justiça e inclui representantes do governo, da Câmara e do Senado, bem como associações profissionais das áreas de interesse - Associação Brasileira de Educação, Associação Brasileira de Imprensa, Conselho Federal da Ordem dos Advogados do Brasil -e especialistas, professores catedráticos de Direito Constitucional e de Direito Penal (web site: www.mj.gov.br). De modo semelhante, especialistas têm assento no Conselho Nacional de Política Criminal e Penitenciária, de 1980, e personalidades e entidades feministas participam do Conselho Nacional dos Direitos da Mulher, de 1985 (idem). Já o Conselho Nacional de Saúde, vinculado ao respectivo Ministério, data originalmente de 1937. Foi recriado em 1990 com novos poderes, enfatizando a participação popular, a descentralização das ações e políticas de saúde e a assistência integral, visando a construção de um "novo modelo público de saúde" (web site: wnw. conselho.saude.gov.br).

Com maior ou menor transparência de gestão, e embora questionáveis quanto à participação efetivamente popular, os diversos conselhos são seguramente canais valiosos para a influência da sociedade civil sobre a atuação do governo. Essa influência será maior nos conselhos que operam a partir dos municípios, porquanto pode-se conferir, in loco, a eficácia da política e as circunstâncias de sua implementação. É nesse contexto que ganha concretude a visão do desenvolvimento sustentado com o "empoderamento" e protagonismo dos beneficiários das políticas setoriais. ${ }^{2}$

Outra virtude dos conselhos é seu potencial de influência contra práticas corruptas. Longa série de escândalos tem demonstrado a ineficácia do controle estatal sobre o uso de fundos públicos em muitas áreas. Naquelas em que se dá uma participação institucional de representantes da sociedade civil, é de se esperar que desempenhem um papel de vigilância pela moralidade no trato da coisa pública.

12. Participação popular direta, "empoderamento" e protagonismo são teses que ganham efetividade exemplar com o orçamento participativo, implementado pelo governo do Partido dos TrabaIhadores - PT -, em Porto Alegre, Santo André e em Belém. 
Tem hoje respaldo quase universal a tese de que o uso de recursos públicos exige vigilância social. Para muitos países latino-americanos, no entanto, é inegável que - junto com um autoritarismo reconhecidamente cultural - várias "caixas-pretas" da administração pública têm resistido à redemocratização, como ilustra a discricionariedade de órgãos da administração nacional argentina. Há pouco mais de um ano, estudo patrocinado pelo Programa das Nações Unidas para o Desenvolvimento - PNUD -, BID e Banco Mundial sobre a necessidade de reformas na legislação que afeta as OSCs naquele país constatou que os obstáculos à plena existência jurídica das associações, como também ao gozo da isenção do imposto de renda, não provêm da lei mas de atos inferiores e do comportamento arbitrário de autoridades do poder executivo (Gadis, Foro del Sector Social, 1999).

Se no Brasil étempo de radicalização da democracia (conceito há muito propugnado pelas $\mathrm{ONGs}$, agora incorporado pelo discurso oficial), o desafio é então maior: zonas cinzentas mesclando o arbítrio e potencial para a corrupção passam a ser intoleráveis em qualquer reduto, dos três poderes, na federação.

\section{Transparência como valor universal}

Zonas cinzentas do aparelho de Estado inspiram justificada preocupação, e elas também se dão nas interfaces de relacionamento das autoridades públicas e OSCs. Este é o caso da ausência de concurso para celebração de "termos de parceria" entre órgãos da administração e OSCs de interesse público (as OSC-IPs), no marco da Lei n.9.790. Problema semelhante oferecem a dispensa de licitação em contratos ordinários, nas hipóteses que a Lei n.8.666 permite a apreciação subjetiva, e o vazio de regulação para a celebração de convênios, instrumento que se mantém como alternativa de acesso a transferências do erário para particulares, a fundo perdido (Oliveira, 1997a, p.62-9). Quanto ao acesso indireto a recursos públicos, pela via da renúncia fiscal, tampouco há publicidade para os processos que permitem aproveitar os grandes incentivos tributários existentes. A imunidade constitucional de alguns impostos, a isenção da contribuição patronal à seguridade social, a captação de doações dedutíveis do imposto de renda e os rentáveis patrocínios em projetos culturais beneficiam poucas OSCs, entre entidades de perfil extremamente variado. ${ }^{13}$

O desvio de recursos da extinta LBA, sob responsabilidade da então primeira dama Rosane Collor, o envolvimento de OSCs de fachada nos negócios dos "anões do

13. OSCs e até OSC-IPs são minoria no acesso a esses incentivos, que vêm privilegiando os fundos de pensão, hospitais e estabelecimentos de ensino que praticam preços exorbitantes, bem como empresas produtoras de espetáculos e mostras, incluindo-se aí produtoras de cinema. 
orçamento", ou as falcatruas entre parlamentares e entidades fantasmas têm gerado escândalos de poucas conseqüências. Para evitar que se repitam, a novidade é a Lei n. 9.790 e o regime posto para as OSC-IPs e suas relações de parceria com o Estado.

De positivo, o regime impõe total publicidade à execução dos termos de parceria. Mas os "órgãos parceiros" de qualquer nível não estão obrigados a anunciar publicamente seu interesse em fazer uso desse instrumento, para quais projetos e com que argumentos de seleção; nada então impede a contratação de entidades criadas com o único intuito de beneficiar-se dessas relações. Por outro lado, no Ministério da Justiça, a autoridade encarregada da qualificação de OSC-IPs não dá publicidade aos requerimentos recebidos e os deferidos ou não e nem divulga seus critérios de análise. Distorções na aplicação da lei passariam, pois, despercebidas. As duas situações permitem violações ao espírito da lei e implicam a possibilidade de apadrinhamento e corrupção. No caso das próprias OSC-IPs, embora a lei determine que dêem publicidade a relatórios financeiros e de atividades à sociedade, não há sistema contábil ou gerencial uniforme que torne úteis essas informações.

Independentemente do regime introduzido pela Lei n.9.790, contudo, a transparência pública é um imperativo para todas as OSCs, por uma série de razões. Têm na sociedade sua origem, público-alvo e fonte de recursos, humanos e materiais. É de seu interesse direto conquistar a opinião pública e gozar da confiança de diversos segmentos. Contando ou não com outros benefícios fiscais, cumulativamente, todas as OSCs têm assegurada a isenção do imposto de renda. Isso se justifica porquanto não se distribui superávit nem patrimônio, não há lucro, e toda receita se destina ao desenvolvimento dos objetivos institucionais. A isenção de impostos, no entanto, implica renúncia de toda a sociedade aos seus benefícios, o que supõe a obrigação, por parte de entidades e empresas isentas, de lhe prestar contas.

Um aspecto crucial para discussão diz respeito à legitimidade. Muito mais do que empresas e entidades sem fins lucrativos, em geral, as OSCs de fins públicos (reconhecidas ou não na condição de OSC-IPs) devem satisfações à sociedade. Pretendem representá-la embora careçam de investidura formal. Têm o dever de reconhecer nela seu stakeholder principal. Não pertencem a um grupo de sócios, controladores ou acionistas, como tampouco ao seu próprio quadro funcional - e sim ao mesmo público externo cujos interesses, direitos ou necessidades são o alvo de suas ações. Obstáculos materiais impediriam uma fiel representação desse público em instância de deliberação interna a cada organização. Inexiste, portanto, o rito da prestação de contas ao principal interessado, e configura-se o que se poderia chamar de um déficit de accountability, nas palavras do diretor da organização Transparency International para a Europa Central e Oriental, Miklos Marschall, "as ONGs têm esse déficit porque não prestam contas a 
acionistas, nem são eleitas pelos segmentos da sociedade civil que dizem representar e esse accountability minus deve ser compensado por um transparency plus". A saída para compensar esse desvio e dirimir a contradição é a transparência pública, na mesma medida em que se exige do Estado. Individualmente ou em grupo, por meio das redes e associações, as OSCs devem construir espaços de crescente visibilidade e de publicidade para os seus atos de gestão (Oliveira, 1998).

Nessa direção aponta a pesquisa Abong/bope, recém-divulgada, sobre a percepção das ONGs - na acepção de designação genérica - pelo público (web site: www.abong.org.br). Número expressivo, mas ainda restrito dos entrevistados (índice de 27\%), conhecia o termo "ONGs". Nesse segmento, o maior índice colhido nas opiniões estimuladas apontou: que elas "possuem um papel fundamental no Brasil de hoje" (23\%); mas "devem prestar contas sobre a origem do dinheiro que recebem" (23\%). E prestariam contas a quem? Entre as alternativas de opinião com maior incidência, duas oferecem quase uma resposta a esta questão: as ONGs "deveriam ser mais fiscalizadas pelo governo" (I 8\%); ou, ao contrário, "são autônomas e deveriam ser fiscalizadas só pela sociedade" (12\%).

Com exceção das fundações, submetidas ao Ministério Público, as OSCs brasileiras são passíveis da mesma fiscalização dos poderes públicos sobre empresas que atuem em área semelhante. Aqui, como em muitos países, o controle estatal tem-se mostrado falho até sobre o próprio aparelho e uso dos recursos públicos - tanto assim que a vigilância da sociedade é imprescindível para a moralidade da administração. A prestação periódica de relatórios e demonstrações financeiras a qualquer órgão governamental não é garantia de supervisão e isso é tão reconhecidamente inócuo que a Lei n.9.790 não contemplou nada parecido para as OSC-IPs. Essas informações devem, isso sim, ser levadas ao conhecimento do público. Ninguém melhor do que a própria sociedade civil, e nela os potenciais doadores e colaboradores, para fiscalizar as OSCs, em geral, e as de interesse público, em particular.

\section{AS ONGS E A EDUCAÇÃO}

Enfocando agora as ONGs brasileiras como classe especial de OSCs, é certo que seu envolvimento com o campo da educação não é novo. Aliás, esse envolvimento está na razão mesma do seu nascimento. Nos anos 60 e 70, um conjunto de pequenas organizações constituídas por grupos de pessoas oriundas dos setores das igrejas, dos partidos políticos e das universidades, organizam-se em entidades - associações civis sem fins lucrativos - para se dedicar ao trabalho social junto aos setores mais pobres da população (Fernandes, 1994). 
Em plena vigência, o regime militar implantado em março de 1964 encerrava um período de intensa mobilização social que envolvera diversos setores da sociedade. $\mathrm{Na}$ pauta dessa mobilização, a disputa sobre o modelo de desenvolvimento e o tipo de sociedade a se constituir no Brasil ocupavam posição de destaque.

As novas organizações tinham como missão principal a reconstrução do tecido social que havia se rompido com a ditadura, a defesa dos direitos humanos e a educação popular. O que se buscava com esses processos educativos era ampliar o nível de compreensão que a população pobre tinha das suas condições de vida, discutindo as suas causas, visando uma atuação crítica na sociedade.

A igreja católica foi um dos espaços mais importantes para os trabalhos de ação junto aos grupos populares com essas características. Nesse contexto, os processos educativos baseavam-se na leitura dos textos bíblicos, adaptando-os à realidade do momento, sob a perspectiva da Teologia da Libertação. As famosas Comunidades Eclesiais de Base eram grupos de ação pastoral e de educação popular.

A reflexão sobre a realidade não ficava restrita apenas a um processo de conhecimento. Ao contrário, o contato direto com a realidade para identificar os problemas existentes determinava, após análise das causas desses problemas, uma intervenção sobre a mesma realidade, visando a sua transformação, a fim de superar os problemas e construir condições de vida mais justas. Nesse sentido, a prática educativa era ao mesmo tempo um ato de organização e mobilização da sociedade.

Como se pode imaginar, o trabalho desenvolvido não tinha visibilidade pública. Era uma ação militante, realizada em um nível microssocial, que se desenvolvia em sigilo e sob o silêncio da censura e da repressão impostas pelo regime militar.

Outra característica desse envolvimento das ONGs com a educação era o fato de que tais processos educativos eram absolutamente desligados dos processos educativos oficiais, ou seja, dos sistemas públicos de ensino. Em razão do regime autoritário, havia muito pouca possibilidade de crítica dentro desses sistemas de ensino e nas suas escolas. Ao mesmo tempo, as orientações das teorias educacionais críticas, daquele momento histórico, viam o trabalho junto às escolas como de caráter reprodutor das ideologias dominantes e muito mais afeito a manter as relações de classe existentes do que a produzir uma nova ordem social. Eram os tempos da sociologia reprodutivista, em que as escolas, consideradas como aparelhos ideológicos do Estado, eram vistas como instâncias de manutenção e reforço das condições de vida da população empobrecida em sociedades capitalistas, como a brasileira.

Naqueles tempos, as ONGs tinham o seu trabalho quase que exclusivamente voltado para o apoio às pastorais de caráter social da Igreja católica. As temáticas variavam 
em razão das necessidades definidas pelos próprios grupos populares: saúde, moradia, analfabetismo, produção, organização etc.

Os processos educativos sofriam grande influência do pensamento pedagógico desenvolvido no período anterior ao golpe, durante os primeiros anos da década de 60, quando as idéias do educador brasileiro Paulo Freire se disseminaram entre centenas de experiências de educação popular, denominadas na oportunidade como "movimentos de cultura popular". As experiências uniam a política com manifestações culturais como teatro, música, poesia. Eram trabalhos educativos, construídos junto com as comunidades carentes, a partir das suas tradições, e que se espalharam por todo o país.

Em linhas gerais, tais orientações pedagógicas se apoiavam na idéia de que os grupos populares detinham um saber particular, que era produzido conforme suas condições de vida, e que os processos educativos ocorriam do encontro entre esses saberes e os saberes dos educadores. Isso se dava pelo diálogo entre o educador e o educando, tomando como base o estudo da realidade local, voltado para a transformação das condições de vida da população empobrecida. A missão educativa de tais educadores não se realizava separada de uma intencionalidade política.

\section{O período de democratização da sociedade brasileira}

Com o final da década de 70 e início da de 80, dois fatores marcaram o trabalho educativo desenvolvido por essa classe e modelo de ONGs. Um deles foi o crescimento de trabalhos sociais no âmbito da sociedade civil, para além das pastorais da igreja católica. Esses novos espaços, muitas vezes produzidos como decorrência da própria atuação das pastorais, ao se tornar independentes de sua influência original, mostravam uma nova complexidade dos atores sociais brasileiros. Eram os movimentos de bairros, as associações de moradores e organizações populares; os movimentos sindicais que se constituíam à margem do movimento sindical oficial; os movimentos de mulheres e o movimento negro; os movimentos autônomos de luta por moradia, terra e trabalho.

Os novos movimentos sociais e populares davam uma nova conformação à sociedade civil. O trabalho das ONGs passou a se realizar também com esses movimentos, apoiando-os na sua organização e mobilização, como também no seu trabalho educativo. As experiências de educação popular produzidas pelas $O N G$ s, no segundo momento, não se ativeram apenas às questões materiais de produção e reprodução da vida, mas voltaram-se também para os temas relativos ao plano cultural e simbólico, como as relações sociais de gênero, etnia e raça. Assim, ao trabalhar com tais movimentos, as ONGs agregavam aos fatores relativos à condição de pobreza e classe os fatores ligados ao universo da produção cultural e simbólica. 
O outro fator que influiu no trabalho educativo das ONGs foi a luta pela construção de um ensino público e de qualidade para a maioria da população. Com a democratização da sociedade, o próprio movimento social colocou entre as suas demandas a questão da escola pública como prioridade no campo do fortalecimento dos grupos populares. Ler, escrever, contar, apropriar-se dos conhecimentos que estavam disponíveis para os outros grupos sociais eram demandas daqueles que não tinham acesso aos serviços de escolarização. Isso já se mostrava claro pelos inúmeros trabalhos de escolarização popular, como programas de alfabetização de adultos, creches, escolas comunitárias, todos desenvolvidos pelos movimentos sociais, sindicatos e pelas ONGs, ou com o seu apoio.

Ao mesmo tempo, havia também uma outra pressão vinda do próprio Estado. Com a democratização das suas instâncias, muitos atores sociais que antes estavam trabalhando no campo da sociedade civil, em atividades de educação popular desenvolvidas pelas $O N G$ s e pelos movimento sociais, foram atuar no sistema público de ensino. Nesse contexto, voltam a repensar uma proposta de escola como demanda da população e voltada para os seus interesses. Não estavam mais em vigência as teorias reprodutivistas que viam a escola como meramente a serviço das classes dominantes. Ao contrário, mesmo reconhecendo que o sistema educacional era desigual e injusto, tratava-se de apropriar-se de seus instrumentos para que atendessem os interesses populares, fazendo com que a distribuição do conhecimento também fosse um ato político de melhoria das condições de vida.

Dessa forma, as ONGs passam a planejar e desenvolver ações de assessoria aos setores públicos, ou, ainda, adotam a luta pelo acesso e qualificação dos serviços públicos de ensino voltados para os interesses populares. Temas como o reconhecimento do direito de haver escolas e creches para todos, melhoria da qualidade do ensino, formação de professores, elaboração de materiais didáticos, elaboração de novos currículos e modelos pedagógicos de interesse dos grupos populares passaram a ser contemplados pelo trabalho das ONGs.

Se, em alguns momentos, a constituição de uma escola popular paralela aos sistemas públicos do ensino poderia ter sido pauta dos movimentos sociais e das ONGs, a verdade é que - dado o caráter institucional dos processos escolares - tais escolas se mostraram inviáveis, a longo prazo, sem um apoio do poder público. Discutem-se, então, mecanismos de controle por parte da sociedade civil sobre as instâncias públicas de ensino. Passa-se a debater a participação dos pais, os mecanismos internos de democratização da escola pública, como os centros cívicos e as associações de pais e mestres. Discutem-se, ainda, mecanismos de parceria entre o Estado e a sociedade, como, por 
exemplo, a garantia, por parte do setor público, de institucionalidade das escolas e, por parte dos movimentos sociais e das ONGs, de orientações pedagógicas.

Há ainda um movimento no sentido de reconhecer práticas educativas dos movimentos sociais como práticas de caráter público, como no caso das escolas comunitárias ou do Movimento dos Trabalhadores Rurais Sem Terra - MST. Nesse caso, exige-se o reconhecimento legal, a destinação de verbas para o pagamento dos professores e o apoio de material didático.

As ONGs ainda exerceram influência nas orientações pedagógicas, seja levando experiência de educação popular desenvolvida nos espaços da sociedade civil para as escolas públicas, seja realizando atividades que pudessem servir de modelos a ser socializados posteriormente nos sistemas públicos.

O movimento mais geral da sociedade apontava para a preocupação de fazer com que o Estado se democratizasse e configurasse como instância provedora de serviços públicos para a população. Essa oferta deveria ser extensiva a todos, ser de qualidade e estar sob controle da população. Essas eram as orientações que movimentos sociais, sindicatos, ONGs e outros atores da sociedade buscavam implantar. Entre os vários serviços, a escola tornou-se um dos mais importantes.

\section{As ONGs e a nova conjuntura}

Nos últimos anos, o Brasil, pressionado pela crise fiscal e pelo desenvolvimento do capitalismo internacional, vem executando um processo de reforma do Estado. Essas orientações gerais no plano econômico produziram uma reversão nas expectativas expressas na elaboração da Constituição de 1988, quando se consagrou a conquista de uma série de direitos inclusive no campo da educação.

As políticas públicas de educação no Brasil vêm se reorganizando em razão dessa lógica. Um dos aspectos mais importantes dos processos de reforma dos sistemas educacionais é a redefinição dos limites entre o público e o privado. Ao redefinir o papel do Estado no atendimento dos direitos educativos, o governo brasileiro, premido pelas limitações econômicas, tem convocado a sociedade civil a exercer essa função pública. Se, antes, a participação da sociedade civil se circunscrevia aos processos de democratização do Estado, pelo seu papel de controle e direcionamento dos serviços públicos, neste momento ela é conduzida a colaborar diretamente com a oferta dos serviços educacionais, na lógica de diminuição das responsabilidades do Estado.

Ao mesmo tempo, verifica-se, no âmbito da sociedade civil, que certas entidades vão ganhando relevância no campo da educação. São entidades filantrópicas ou de caráter assistencial, chamadas a colaborar com o Estado, deslocando parte da responsabi- 
lidade pelo sistema escolar do plano das políticas universais públicas para o plano das políticas compensatórias. É o caso da educação de adultos e da educação infantil, que foram deixadas de lado dentro das prioridades da oferta dos sistemas públicos e vêm sendo alocadas como responsabilidade das organizações da sociedade civil e mesmo dos indivíduos.

Na sociedade brasileira também vem crescendo o interesse de parte dos grupos empresariais e do capital, em geral, nos rumos e no controle das orientações e do atendimento educacionais. Há uma proliferação de institutos e fundações de empresas privadas, constituídas muitas delas com base nas isenções fiscais, quase todas mantendo a educação como uma das suas atividades principais. A forte presença do capital no plano das ações sociais e da educação, em particular, demonstra duas faces contraditórias. De um lado, tal envolvimento aponta para um importante compromisso social de parte do capital, compromisso fundamental em sociedades como a brasileira, com elevada concentração de renda e considerável desnível social. Mas, ao mesmo tempo, aponta também para um crescente descomprometimento do setor público com a educação, correndo-se o risco de rompimento de um dos aspectos mais importantes na construção da democracia social brasileira.

É dentro desse panorama geral que as ONGs tradicionais vêm sendo chamadas a colaborar: tanto na ação direta de oferta dos serviços educacionais, em que o Estado se retira ou não entra, como em decorrência da redução do corpo técnico das diversas secretarias, na produção de materiais didáticos, capacitação de professores e atuação no plano das orientações pedagógicas.

Há um risco neste momento de que a participação das ONGs se dê no rumo do esvaziamento do papel do Estado na área social, assumindo responsabilidades por ações antes nas mãos dos setores públicos, particularmente, em uma conjuntura de diminuição dos recursos da cooperação internacional. Ao mesmo tempo, contraditoriamente, em uma situação de desmonte dos serviços públicos, a atuação das ONGs no campo da educação pode ajudar na qualificação das ações educacionais oferecidas pelo Estado, garantindo o seu fortalecimento.

Sobre os desafios produzidos pela conjuntura atual, o depoimento a seguir, citado em documento produzido pelas ONGs de Educação do Estado de Minas Gerais, em encontro realizado para discutir as atividades no contexto das recomendações da Conferência Educação para Todos, fala por si:

...cada vez mais se impõe a necessidade de elaborarmos propostas para o conjunto da população, sempre maior que aquelas que trabalhamos cotidianamente. Isto implica muitas vezes em repensarmos nossas práticas, seus conteúdos, metodologias 
etc. Isto porque, muitas vezes, à viabilidade técnica de uma proposta nem sempre corresponde uma viabilidade política, e vice-versa. Ou, em outras palavras, elaborar propostas viáveis implica em viabilizá-las técnica e politicamente ao mesmo tempo. ...Propor projetos viáveis política e tecnicamente implica, para as ONGs, dar um passo avante na formatação técnica de suas experiências e, por outro lado, buscar articulação política necessária à sua imposição na agenda de debates.

\section{$[\ldots]$}

Este duplo movimento poderia ajudar-nos na superação, de uma vez por todas, da idéia do papel apenas alternativo das ONGs. Se, no momento histórico de seu nascimento e fortalecimento, boa parte das ONGs tiveram que reforçar seu caráter alternativo ao Estado e a outras iniciativas ditas "assistencialistas", hoje, é preciso, com lucidez, dizer que isto não basta. Isto não basta porque as ONGs, por sua ligação com a população, por sua capacidade de articular-se politicamente, pela experiência acumulada, não podem se furtar ao dever de propor alternativas viáveis para o conjunto da população.

\section{$[\ldots]$}

Dizer isto não implica, de modo algum, que todos agora deixemos nossas práticas e nossas referências (alternativas ou não) e passemos para o campo do "político e tecnicamente viável”. Pelo contrário. É preciso fortalecer o campo das experiências que ocorrem fora do aparelho estatal, mas só que agora não apenas para servir-lhe como alternativa, mas também como parâmetro...

...é preciso, a muitas ONGs de diversas naturezas, compreender que na verdade elas já participam e são parte da política pública. Isto por dois motivos: em primeiro lugar porque nos últimos anos temos construído na América Latina um sentido do público que ultrapassa o estatal, inclusive para questionar um Estado que tem sido muito pouco público. Por outro lado, boa parte das ONGs se mantém com algum tipo de recurso público, seja este estatal ou não.

\section{$[\ldots]$}

Assumir este caráter público traz para as ONGs (...) propor e discutir a partir de dentro das políticas públicas e não apenas como alguém de fora do aparelho estatal. Isto seria condição, também, para que as ONGs não sirvam apenas de "correia de transmissão" ou executores de políticas definidas por técnicos e burocratas, mesmo que bem intencionados. 
Afirmar o caráter público das ONGs e sua legitimidade em propor e viabilizar políticas públicas, implica, hoje, numa capacidade de formular uma crítica fundamentada na idéia de privatização dos serviços estatais. Não podemos legitimar as idéias de que os Estados na América Latina devem privatizar como meio de resolver os graves problemas econômicos e sociais pelos quais passamos.

\section{$[\cdots]$}

Finalmente, não é desconhecido de ninguém que trabalhe na área da educação a famosa afirmação que o acesso à escola, nas últimas décadas, foi democratizado, mas a permanência e o acesso aos conhecimentos transmitidos por ela não o foram.(...) Pensar a qualidade da educação escolar para as ONGs deve significar pensar numa experiência que, incorporando a aprendizagem de conhecimentos, seja muito mais do que isto: seja também elemento formador e potencializador das várias dimensões do ser humano. Só conseguiremos realizar esta tarefa se tirarmos a discussão da qualidade, em educação, do campo da lógica do mercado e da produção. É preciso discutir eficiência, produtividade e outras categorias, não na forma como foram elaboradas para dar conta de processos produtivos, a lógica do mercado, mas na lógica das relações sociais e culturais que se dão, em última instância, nas relações pedagógicas no interior da escola. (Faria Filho, 1994, p. 17)

\section{REFERÊNCIAS BIBLIOGRÁFICAS}

BORGES, S. Mais rigor no combate à "farra das subvenções". Jornal do Commercio, Recife, 19 mar. 2000.

CONSELHO DA COMUNIDADE SOLIDÁRIA. Um novo referencial para a ação social do Estado e da sociedade: sete lições da experiência da comunidade solidária. Brasília. 2000. mimeo.

FARIA FILHO, L. M. Educação para todos: quais os desafios para as ONGs? Ongs e Educação. Belo Horizonte: Unicef/FDDCAMG, 1994.

FERNANDES, R. C. Privado porém público: o terceiro setor na América Latina. Rio de Janeiro: CIVICUS; Relume-Dumará, 1994.

GADIS, FORO DEL SECTOR SOCIAL. Las Organizaciones de la sociedad civil en el ordenamiento legal argentino: cuatro propuestas para el cambio. Buenos Aires: BID; Banco Mundial; PNUD, 1999. 
GARRISON, J. From collaboration to confrontation: civil society/government/World Bank relations in Brazil. Washington: The World Bank, 2000.

HADDAD, S. Educação escolar no Brasil. In: BITTENCOURT, A., DANTAS, I. (ed.). As Faces da pobreza no Brasil. programa de trabalho. Rio de Janeiro: ACTIONAID, 1999. p. I13-78.

. Experiências em alfabetização na sociedade civil: projeto de alfabetização com seringueiros no Acre. Idéias, São Paulo: FDE, n. I, 1992.

IRELAND, T. D. Escola Zé Peão: uma prática educativa com operários da construção em João Pessoa. Alfabetização e Cidadania, São Paulo: RAAB, n. 4, 1996.

LANDIM, L. A Invenção das ONGs: do serviço invisível a profissão sem nome. Rio de Janeiro: Museu Nacional; Universidade Federal do Rio de Janeiro, 1993.

LANDIM, L., BERES, N. As Organizações sem fins lucrativos no Brasil: ocupações, despesas e recursos. Rio de Janeiro: Nau Editora, 1999.

LANDIM, L., COTRIM, L. L. ONGs. um perfil; cadastro das filiadas à Associação Brasileira de ONGs (ABONG). São Paulo: ABONG; ISER, 1996.

LANDIM, L., FERNANDES, R. C. Sem fins lucrativos: as organizações não-governamentais no Brasil. Rio de Janeiro: ISER, 1988.

OLIVEIRA, A. C. La Autorregulación de las OSCs. Un Marco Jurídico para la participación ciudadana: memoria, III Taller Regional Centroamericano. San José: Fundación Arias para la Paz y el Progreso Humano, 1998. p. 70-82.

. Elementos para la consolidación de las OSCs en sudamérica. In: OLIVEIRA, A.C. (org.) Marco regulador de las organizaciones de la sociedad civil en sudamérica. Washington: BID; PNUD, 1997a. p. 3-26.

. National integrity systems, the TI sourcebook. Berlin: Jeremy Pope, 1999.

. Sobre o Projeto de Lei n. 4.690/98, de 28/7/98. Rede de Informações do Terceiro Setor - RITS, 1998a. mimeo.

. Terceiro setor: uma agenda para reforma do marco legal. Brasília: Comunidade Solidária, 1997a.

PNUD, BID. El Capital social: hacia la construcción del índice de desarrollo sociedad civil en Argentina. Buenos Aires: Edilab Editora, 1998.

PUTNAM, R. Making democracy work. Civic Traditions in Modern Italy. Princeton: Princeton University Press, 1993.

REIS, S. A. Democracia na escola pública: escolas comunitárias. 1998. mimeo. 